\title{
Evidence of an Archetypal Management Framework: An Exploratory Examination of Commonality Among Existing Management Frameworks and Resulting Efficacy
}

\author{
William Donaldson ${ }^{1}$ \\ ${ }^{1}$ Christopher Newport University \\ Keywords: management, archetype, enterprise management, management framework, small business \\ https://doi.org/10.53703/001c.28165
}

\section{Small Business Institute Journal}

Vol. 17, Issue 1, 2021

\begin{abstract}
The burgeoning management science fields have produced and continue to produce vast quantities of advice, frameworks, and checklists for owners, leaders, and managers. Systems scientists have long proposed that systems, both natural and human-made, significantly drive individual behavior within the system and exhibit repeating structures and patterns known as archetypes. Systems do so because the archetypal patterns are fundamental to the system's dynamics. Enterprises represent a specific class of socio-technical systems, which have been studied using management and social science disciplines. Evidence is emerging that the proliferation of management science may be overwhelming, that the advice is not sufficiently integrated, and only addresses discrete parts of the enterprise, not the whole enterprise system. One would expect to find evidence of repeating patterns in the general class of socio-technical systems known as enterprises. This article is an exploratory analysis of existing management frameworks and researches the evidence for an archetypal construct that may be beneficial to small, and large, business managers. The author presents evidence of such an archetype, thereby building on general management theory that is helpful in assisting management thought in complex environments. Finally, the author proposes a framework for management based on the findings. Using the common elements of the proposed framework, owners and senior managers were surveyed to determine whether using such an archetype as a system and in a systematic way enhanced enterprise performance. Implications for owners, managers, board members, and academics are discussed.
\end{abstract}

\section{INTRODUCTION}

Enterprises represent the most prevalent type of systems in the worldwide economy, far greater in number than other complex systems (Rouse, 2005). These enterprises represent complex, adaptive, socio-technical systems (Gharajedaghi, 2006). They are ubiquitous and involve and impact a vast number of humans every day (Checkland, 1999; Pennock \& Rouse, 2016; Rouse, 2011). As of 2015, there were over 5.9 million small business firms in the United States (Statistics of U.S. Businesses (SUSB), 2015). The National Center for Charitable Statistics reports over 1.5 million charitable organizations in the United States (NCCS Core Statistics, 2015). According to the US Small Business Administration, small businesses create $64 \%$ of the net new jobs and employ $47 \%$ of the country's private workforce (2018). Extending these numbers beyond the US, the ubiquity and importance of this class of enterprises are evident.

Enterprises, as complex adaptive socio-technical systems, are notably hard to manage and stubbornly resistant to change precisely because they are complex, adaptive systems (de Weck et al., 2011; Hoebeke, 1994; Kotter, 2007; Rouse, 2011). At the enterprise level systems dynamics tend to dominate (Hoebeke, 1994; Rouse, 2011). Further, W. Ed- wards Deming found that upwards of $94 \%$ of all errors, defects, mistakes, misunderstandings in the enterprise were systemic (Deming, 1982, 1994); people in the system wanted to do the correct thing, but were led astray by the system. Management is the systems architect and thus cannot escape culpability for these findings (Gharajedaghi, 2006; Hoebeke, 1994). The Gallup Organization's survey findings offer evidence of systemic underperformance. The Gallup organization surveys companies every year for employee engagement. In 2015, 50.3\% of the employees surveyed responded they were disengaged at work, and $16.8 \% \%$ said they were actively disengaged (Adkins, 2016). In all, more than $67 \%$ of the respondents indicated they were disengaged from the system; results predicted by systems thinkers as far back as the 1970s (Ackoff, 1971; Checkland, 1971; Churchman, 1979; Senge, 1990b).

Systems thinking has been described as "the discipline that integrates the discipline” (Senge, 1990a). Therefore, this research is of particular importance because it has the potential to affect all the management disciplines at the enterprise level - the strategic level. A better understanding of an archetypal management structure can only be of help to each of the discrete management and social science disciplines. 


\section{TOO MUCH, AND NOT ENOUGH, MANAGEMENT ADVICE?}

A review of the relevant literature and a search of the disciplines reveal many useful models specific to planning, strategy, marketing, human resources, project management, risk management, resource management, engineering management, and many more management areas. All these models are useful for managing portions of the enterprise, or processes therein, but fall short of offering holistic, enterprise-level system models or frameworks.

\section{MANAGEMENT MODELS}

From all the management literature, many models have emerged to cope with managing the complex, adaptive, socio-technical systems we call enterprises. It is beyond the scope of this review to look at each management model. However, it is instructive to explore the underlying nature of the models and their use.

Marshak summarizes many of the most common managerial models and draws the following conclusions (Keenoy et al., 2000):

1. The models contain many of the same elements, but with different orientations and emphases.

2. The models contain several elements in the range from four to twelve, but most commonly contain between five and seven.

3. They contain implicit or explicit interaction and interrelationships among the elements.

4. Each model omits elements advanced as critical by other models or that other schools of thought emphasize.

Keenoy et al., discuss the importance of a common set of elements and a common understanding of these elements and their interaction as critical to organizational discourse and managerial success, regardless of firm size (Keenoy et al., 2000). This research reiterates Senge's findings on the importance of common mental models, holons, team learning, and systems thinking (Senge et al., 1994). The importance of these unifying themes is demonstrated in the preponderance of corporate universities found in leading companies worldwide (Abel \& Li, 2012). These internal universities are designed specifically to teach the common elements, common mental models - constructs, frameworks unique to the specific business (Rouse \& Morris, 1986; Senge, 1990b), common language and understanding of a holistic management system (Allen, 2002). In teaching these common elements in a Socratic way, these universities are, by default, capturing Checkland's notion of using Koestler's holons to structure learning, debate, and understanding (Checkland, 1999; Koestler, 1967; Stewart et al., 2005; Storey, 2004).

"The prime systemicity lies in the process of inquiry rather than in the real world, as is assumed in hard systems thinking, which attempts to model the real world. In soft systems methodology, the models of human activity systems are holons used as devices to structure coherent debate (Checkland \& Haynes, 1994).”
All of the prior foundational work has led to a broad understanding of the management disciplines (Collins, 2001; Deming, 1994; Drucker, 2001; Kaplan \& Norton, 2008; Quigley \& Hambrick, 2015; Wheatley, 2006). However, the sheer number and proliferation of management models have proven to be problematic, as managers face an overwhelming array of models from which to choose (Drucker, 2001; Porterfield, 2009; Schwaninger, 2001). In addition to the sheer volume, the management disciplines suffer from the same schisms and reductionist tendencies as befell earlier academic efforts in the natural and social sciences (Churchman, 1979; Deming, 1994; Jackson, 2003). Much of management thought, and practice is designed to optimize certain discrete functions within the organization - finance, human resources, marketing, etc. This concept, known in system thinking as point optimization, or suboptimization (Meadows, 2008), is anathema to good systems thinking as managers strive to optimize their area of influence (point optimization) often at the expense of the whole enterprise, the system (Goldratt, 1984; Meadows, 2008; Rouse, 2011). Yet the disciplinary structure of the academy almost assures a lack of inter-disciplinarity (Churchman, 1979). As Arnold and Lawson point out, business and management curricula are almost totally devoid of systems thinking elements (Arnold \& Lawson, 2004).

W. Edwards Deming and Peter Drucker, two of the most influential management thought leaders, wrote extensively on the need for managers to be more well-rounded and more holistic in their thinking. In topics ranging from leadership to globalization, accounting to research, manufacturing to supply chain, they espoused a more systemic view (Deming, 1982, 1994; Drucker, 2001). Collins and Porras identified the characteristics of successful organizations, including a more inclusive view and some of the concepts embodied in Churchland's soft systems methodology (Churchman, 1979; Collins \& Porras, 1994). Collins furthers these ideas identifying the traits, many that are mirrored in systems thinking that allowed companies to make transformational moves in their industries (Collins, 2001). From the systems engineering realm, Rouse explores the business management implications of enterprises as systems. He explores the essential challenges that are inherent in the dynamics of a constantly changing environment and how firms can use systems concepts for enterprise transformation (Pennock \& Rouse, 2016; Rouse, 2005). Kaplan and Norton presented a broader, more holistic performance management concept, The Balanced Scorecard, that included measures generally considered to be the soft side of management (Kaplan \& Norton, 2007, 2008).

\section{IT ONLY MATTERS IF THE SYSTEM LEARNS}

Management scientists have described the various phenomena by which elements of complex, adaptive, socio-technical systems learn and grow, either by design or by default (Chan, 2009; Fyock, 1999; Senge, 1990b). However, the notion that an enterprise is a system is not a universally accepted construct in the business management community (Atwater et al., 2008; Senge, 1990b). Senge advances the notion that systems thinking is the missing link - the "Fifth Discipline” - that enables, organizational learning as dis- 
tinct from individual learning (Senge, 1990a). Senge is largely responsible for awakening, or re-awakening, the business community to systems thinking. Despite the commercial success of Senge's book, there remains little evidence that mainstream business management disciplines have integrated systems thinking. Atwater et al. report that a comprehensive treatment of systems thinking is lacking in graduate and undergraduate management programs (Atwater et al., 2008).

Another area Senge promoted was team learning. Levitt and March, from the Sociology and Business schools at Stanford, wrote about organizational learning before Senge. They clearly articulate many of the same concepts of systemic learning as Senge; however, they do not use the term systems thinking (Levitt \& March, 1988). Slowly the worlds of business management and systems thinking are coming together, and the enterprise is the meeting place. Bardoel explores the importance of applying systems thinking tools in organizational behavior training (Bardoel \& Haslett, 2004). Segatto et al. advance the concept of systems thinking into the area of business process management (Segatto et al., 2013).

\section{TOWARDS A COMMON SET OF ELEMENTS - AN ARCHETYPE}

The profusion of management thought, and frameworks make system learning harder, by offering management new novel mental models with which to frame the enterprise. Many business owners and managers, of enterprises small and large, employ these "new" tools and new language to tackle the same problems as before, leading to confusion, not clarity (Ackoff, 1999; Hoebeke, 1994; Jick \& Peiperl, 2010; Pennock \& Rouse, 2016; Rouse, 2011). Termed management by best seller, this constant resetting of the frameworks or methods often does more harm than good (Drucker, 2001; Porterfield, 2009).

\section{INTENT OF THIS RESEARCH}

The intent of this research is to explore the evidence of an archetypal management system. If such a model exists, owners and managers of enterprises of all size can focus on these most important elements and the system in which they are deployed.

\section{RESEARCH METHODOLOGY}

The following research questions guided the exploration onto the existence of an archetypal management model or framework.

(1) Is there sufficient commonality and overlap in existing business enterprise management models to evidence a common set of framework elements, an archetype?

(2) Do companies that apply the common management elements identified in the extant business management models in a systematic way exhibit better performance?

The complexity of the research required the employment of a multi-phase research methodology. The phases were as follows:

(1) An extensive literature review and analysis of exist- ing, most prevalent management models and frameworks from the areas of general management, strategic management, change management, project/program management, human resources management, organizational behavior, and the social sciences.

(2) Extensive content and affinity analysis of the most common frameworks found to develop a set of generalized management elements, which form the definitional elements of the survey and semi-structured interview instruments.

(3) Semi-structured interviews with owners and chief executive officers of companies known to use a management system incorporating some or all the common elements to verify usage and efficacy of the framework and elements.

(4) Repeating phase 2 repeatedly to confirm evidence of an archetypal management model.

\section{ADVANCING MANAGEMENT THEORY THROUGH QUALITATIVE, EXPLORATORY RESEARCH}

Critics of often debase qualitative research soft and imprecise, instead demanding the certitude of quantitative research. However, complex adaptive systems are too complex to yield to such certitude, there are too many independent variables. Therefore, management theorists propose certain heuristics, rules of thumb, schemas, and frameworks to help managers grasp the totality. However, the sheer volume of such heuristics and schemas appears to be a problem (Drucker, 2001; Porterfield, 2009). The author proposes that advancing the theory of an archetypal management model will help focus future management thought and research.

\section{EVIDENCE OF ARCHETYPAL MANAGEMENT ELEMENTS}

To determine the most prevalent management elements in use, internet searches were initially conducted to identify images of frameworks or models using the following terms - strategic management model, strategic management system, enterprise management model and enterprise management system. Initial searches captured additional terminology, so the searches expanded to include change management, risk management, project management, and human resource management models and frameworks. Initial raw search results yielded over 2,400 potential images. Using the following criteria further narrowed the initial results:

- The image must be a graphical representation of a management model or system with distinct, named management elements (versus text, photographs, graphs, etc.);

- The model must have at least three distinct management elements;

- There must be no evidence of overlap (e.g., identical elemental structures utilizing a different name).

Applying the above criteria, the potential management frameworks were reduced to an initial set of 169 for further study. Using literature searches and review, these were further filtered by requiring that the model must be directed at managing all or part of the enterprise (e.g., not a framework 
Table 3-1. Management Model Search Frequency

\begin{tabular}{|l|l|c|c|}
\hline Model & Name & Frequency & Rank \\
\hline McKinsey & Seven S Model & $2,270,000$ & 1 \\
\hline Kaplan & Balanced ScoreCard & 555,100 & 2 \\
\hline Blake \& Mouton & Managerial Grid & 65,000 & 3 \\
\hline Burke \& Litwin & Causal Model of Performance and Change & 50,100 & 4 \\
\hline Freedman & Swamp Model of Socio Technical Sytems & 49,800 & 5 \\
\hline Galbraith & Star Model & 44,400 & 6 \\
\hline Kotter & Org. Dynamics Model & 30,400 & 7 \\
\hline Hanna & Org. Performance Model & 27,100 & 8 \\
\hline Kilmann & Five Track Model & 26,000 & 9 \\
\hline Bolman \& Deal & 20,900 & 10 \\
\hline Leavitt & Four Frames Model & 19,700 & 11 \\
\hline Morgan & Diamond & 13,200 & 12 \\
\hline Nadler \& Tushman & Metaphors & 8,680 & 13 \\
\hline Weisbord & Congruence Model for Diagnosing OB & 2,820 & 14 \\
\hline
\end{tabular}

for inventory numbering or bill of material structure, risk management, etc.) leaving seventy-one management models for rigorous analysis. Next, the verbiage of every element of all seventy-one models was content analyzed for raw numbers of repetitions. One hundred eighty-seven different terms used six hundred thirty times (an average of 4 elements per model) were analyzed using standard numerical content analysis techniques - counting and summing occurrences. These terms were further subjected to affinity analysis to eliminate overlap and concentrate on generalizable terms. For example, the terms plan, planning, and strategic planning were all ranked among the top elements and were subsequently reduced to the element 'strategic planning.' This affinity analysis further refined the elements to the following common management elements Leadership, Corporate Culture, Developing People, Strategic Planning, Structure, Control and Governance.

Note: after the conclusion of the initial research, subsequent student researchers with no prior contact or access to early work repeated the precise research methodology serially to verify the results. The following results are from the final research round, but all rounds had similar findings, including the ranking of most popular frameworks and most common elements.

Figure 3-4 summarizes the findings.

In the next step, the most common management models, as revealed by the literature searches and review, were specifically searched by name to determine the frequency of citation. It should be noted that citation volume used as a proxy for usage is a technique popularized by Page, Brin, et al. (Page et al., 1999).

Table 3-1 reflects the results.

All of the models from Table 3-1, and the literature associated with them, were analyzed to determine the intent and scope of usage of the individual elements embodied in each one (Blake \& Mouton, 1969; Bolman \& Deal, 1984; Bryan, 2008; Burke \& Litwin, 1992; Freedman, 2011; Gal-

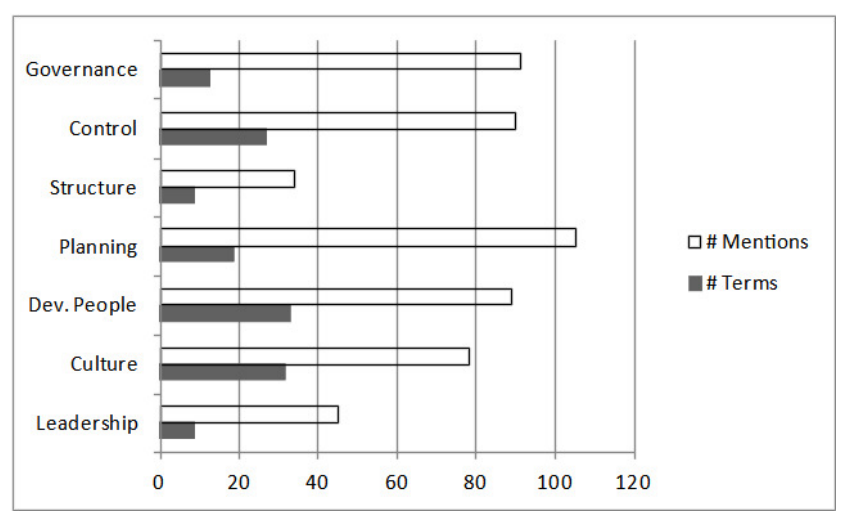

Figure 3-4. Results of Content and Affinity Analysis

braith, 2002; Hanna, 1988; Kaplan, 2005; Kilmann, 1986; Kotter, 2007; Leavitt, 1962; Morgan, 1980; Nadler \& Tushman, 1980; Weisbord, 1976). Table 3-2 below maps the overlap of the most commonly used management models and the most common elements as identified in the content and affinity analysis.

\section{SUMMARY OF ARCHETYPAL ELEMENT RESEARCH}

The research and literature review resulted in a clear articulation of elements common to the most often used management frameworks. These common elements do not represent a mutually exclusive, collectively exhaustive (MECE) set of elements or a framework for all management purposes, just the most common elements of the most common frameworks, and therefore evidence of an enterprise archetype. The following definitions of these elements are not intended to be prescriptive or definitive for any purpose other than establishing a common reference language for the survey and interview recipients in the next phase of the research. This methodology for generalization was used to 
minimize or eliminate any bias on the part of the participants for a particular embodiment of the elemental terminology or for specific management frameworks or set of elements that may have been in use, previously used, or preferred by the participating CEOs, (Creswell, 2003; Leedy, 1997; Yin, 2014). For the purposes of conducting the semistructured interviews, the archetypal elements were defined for the participants as follows:

(1) Leadership - A formal method of developing and assessing leadership and leadership potential, both current and future, within the enterprise.

(2) Organizational Culture - A formal method of developing and assessing organizational culture, both current and future, within the enterprise.

(3) Development of Personnel - A formal method of developing and assessing the skills and capabilities, both current and potential, within the enterprise.

(4) Strategic Planning - A formal, cross-functional teambased method for planning for the future of the enterprise.

(5) Organizational Structure - Clear representation of all the organizational structure elements embodied within the enterprise.

(6) Control Systems - All the visible, demonstrable systems that monitor enterprise performance.

(7) Governance - The enterprise system used to govern, including the board of directors.

\section{EVIDENCE OF ARCHETYPAL SYSTEM FRAMEWORK AND EFFICACY}

To test the hypothesis that the elements, when assembled into a framework and used systematically led to better enterprise performance, the author conducted semi-structured interviews with owners and chief executive officers.

\section{SEMI-STRUCTURED INTERVIEWS WITH OWNERS AND CEOS}

The next phase of the research involved interviewing owners and CEOs of companies known to use one of the common management models, identified in Phase 1 and containing at least five, if not all, of the common elements, found.

\section{SEMI-STRUCTURED INTERVIEW INSTRUMENT DESIGN AND TESTING}

Interview questions were carefully designed to provide insight into the research questions posed. The instruments were reviewed before use by business owners, CEOs, and business consultants known to utilize commonly used frameworks identified in the literature search to verify language and clarity (Whiting, 2008). Following review by the business advisors, the Institutional Review Board at George Washington University (GWU-IRB) approved the instrument for use.

\section{SEMI-STRUCTURED INTERVIEW POPULATION AND CONDUCT}

Utilizing independent business consultants with client

\begin{tabular}{|c|c|c|c|c|c|c|c|}
\hline Model & 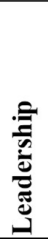 & 总 & 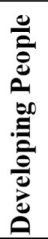 & 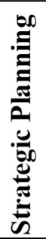 & 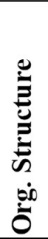 & 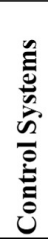 & 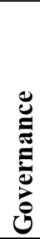 \\
\hline McKinsey & & $\mathrm{X}$ & $\mathrm{X}$ & $\mathrm{X}$ & $\mathrm{X}$ & $\mathrm{X}$ & \\
\hline Kaplan & & $\mathrm{X}$ & $\mathrm{X}$ & $\mathrm{X}$ & & $\mathrm{X}$ & \\
\hline Blake \& Mouton & $\mathrm{X}$ & $\mathrm{X}$ & $\mathrm{X}$ & & & & \\
\hline Burke \& Litwin & $\mathrm{X}$ & $\mathrm{X}$ & $\mathrm{X}$ & $\mathrm{X}$ & $\mathrm{X}$ & $\mathrm{X}$ & \\
\hline Freedman & & $\mathrm{X}$ & $\mathrm{X}$ & $\mathrm{X}$ & $\mathrm{X}$ & $\mathrm{X}$ & $\mathrm{X}$ \\
\hline Galbraith & & $\mathrm{X}$ & $\mathrm{X}$ & $\mathrm{X}$ & $\mathrm{X}$ & $\mathrm{X}$ & \\
\hline Kotter & & $\mathrm{X}$ & $\mathrm{X}$ & $\mathrm{X}$ & $\mathrm{X}$ & $\mathrm{X}$ & $\mathrm{X}$ \\
\hline Hanna & $\mathrm{X}$ & $\mathrm{X}$ & $\mathrm{X}$ & $\mathrm{X}$ & $\mathrm{X}$ & $\mathrm{X}$ & \\
\hline Kilmann & $\mathrm{X}$ & $\mathrm{X}$ & $\mathrm{X}$ & $\mathrm{X}$ & $\mathrm{X}$ & $\mathrm{X}$ & \\
\hline Bolman \& Deal & $\mathrm{X}$ & $\mathrm{X}$ & $\mathrm{X}$ & & $\mathrm{X}$ & & \\
\hline Leavitt & & $\mathrm{X}$ & $\mathrm{X}$ & $\mathrm{X}$ & $\mathrm{X}$ & $\mathrm{X}$ & \\
\hline Morgan & $\mathrm{X}$ & $\mathrm{X}$ & $\mathrm{X}$ & & $\mathrm{X}$ & & $\mathrm{X}$ \\
\hline Nadler \& Tushman & & $\mathrm{X}$ & $\mathrm{X}$ & $\mathrm{X}$ & & & \\
\hline Weisbord & $\mathrm{X}$ & & $\mathrm{X}$ & $\mathrm{X}$ & $\mathrm{X}$ & & \\
\hline
\end{tabular}

Table 3-2: Element Coverage Commonality

bases known to use common business management frameworks including the elements (Leedy, 1997), one hundred and thirty-one contacts were made across all industries, sizes, and ownership types and screened for participation (Creswell, 2003). Thirty-seven CEOs initially agreed to participate and received the survey instrument. Twenty-three semi-structured interviews were conducted $(62.1 \%$ response rate). Interview participants received an email containing the research instrument and were asked to fill it out in advance and to provide a convenient date and time for the formal interview. Sending the questions in advance helps to eliminate biases and steering that may be introduced by the interviewer in the live interview (Cachia \& Millward, 2011). During the conduct of the actual interview, the interviewer verified the respondents' answers and offered the respondents an opportunity to expand upon their answers and clarify any areas of confusion. A secondary benefit of this approach was the development of a fuller and more nuanced understanding of the field of research than is possible with a traditional blind survey (Whiting, 2008).

\section{DESIGN OF RESEARCH PLAN TO ELIMINATE BIAS}

The researcher must be very careful not to introduce bias into the research, especially when utilizing multi-phase, qualitative, or mixed methods (Creswell, 2007). Careful consideration was given to this concern in the development of this research methodology. Specific safeguards employed to combat the introduction of bias were as follows:

1. Generating the generalized set of elements using multiple search, content, and affinity analysis techniques to ensure veracity and subsequent verification of results with literature research.

2. Utilizing a generalized set of management elements for all research instruments to a) ensure consistency throughout the phases, and b) ensure individual or in- 
Table 4-8. Management Element Respondent Profile

\begin{tabular}{|l|c|}
\hline Representative Titles & CEO, Owner, Partner, COO \\
\hline Average number of years experience in role & 14 \\
\hline Revenue Range & $\$ 7$ Million - \$3.5 Billion \\
\hline Average Revenue Growth Rate & $116 \%$ \\
\hline Profit \% Range & $-106 \%$ to $765 \%$ \\
\hline Average Profit Growth Rate & $95 \%$ \\
\hline Average Revenue Per Employee Growth Rate & $60 \%$ \\
\hline
\end{tabular}

Table 4-9. Individual Element - Effect on Business

\begin{tabular}{|c|c|c|c|c|c|}
\hline \multicolumn{6}{|c|}{ Element Effect on Business } \\
\hline & Mode & Med & Min & Max & St Dev \\
\hline Leadership & 5 & 5 & 3 & 5 & 0.6 \\
\hline Organizational Culture & 5 & 5 & 4 & 5 & 0.5 \\
\hline Development of Personnel & 5 & 4 & 3 & 5 & 0.7 \\
\hline Strategic Planning & 5 & 5 & 3 & 5 & 0.6 \\
\hline Organizational Structure & 4 & 4 & 3 & 5 & 0.5 \\
\hline Control Systems & 4 & 4 & 3 & 5 & 0.6 \\
\hline Governance & 5 & 4 & 2 & 5 & 1 \\
\hline
\end{tabular}

stitutional biases to specific management models or frameworks were avoided (Creswell, 2003).

3. Verifying the practical utility and efficacy of the generalized elements to ensure that later phase research explored reaction to known efficacious elements and not theoretical efficacy only (Leedy, 1997).

4. Utilizing the semi-structured interview method of sending the research instruments in advance to eliminate live survey and interviewer bias (Cachia \& Millward, 2011; Whiting, 2008; Yin, 2014).

\section{FINDINGS FROM ENTERPRISE CEO INTERVIEWS}

Table 4-8 characterizes the respondents to the semi-structured interviews conducted with CEOs concerning enterprise performance. Categories include title, average tenure, revenue range, and growth rates.

One hundred percent (100\%) of the owners and CEOs indicated the common management framework elements helped to optimize their business, and eighty-five percent (85\%) said they teach it as a system of management. Seventy-nine percent (79\%) indicated they teach it to all of their employees. Eighty-five percent (85\%) of the respondents felt the model was generalizable and was applicable across divisions, companies, and industries. On average, they rated the effect on the business of using a defined management system with clearly defined management elements as transformative (Likert Level mode $=5$ ). $\underline{\text { Table 4-9 }}$ below summarizes the results from each element individually.
Echoing the findings in the literature review, the most important elements were found to be those from the soft systems methodology. The lowest scoring individual elements were the more traditional and predictable structural and control elements, yet even here, respondents deemed them to have a large positive effect. While the mode was a five and the median was a 4 , one element, Governance, scored a minimum rating of two, no effect on enterprise performance. The score was only from two respondents out of twenty-three (9\%). Further analysis of these interviews indicates these two respondents are in partnership structures. In such structures the partners represent both leadership and governance (Kumar \& Zattoni, 2014) possibly leading to a perceived redundancy in the survey question for these respondents. This duality may explain the low minimum score for the Governance element and hence the larger variability.

\section{EXTENT OF PRACTICE WITHIN THE ENTERPRISE}

The respondents rated the degree to which a defined management system was practiced within the enterprise as foundational to the business (Likert Level mode $=5$ ). Table 4-10 summarizes the results for the individual elements.

\section{FINANCIAL PERFORMANCE AND ANECDOTAL AND EXPERT OPINION OF EFFICACY}

Financial results are the traditional measures used to assess efficacy and performance in a business enterprise. For this 
Table 4-10. Degree of Practice within Enterprise

\begin{tabular}{|l|c|c|c|c|c|}
\hline \multicolumn{7}{|c|}{ Element Degree Practiced } & \multicolumn{2}{c|}{ Max } & St Dev \\
\hline & Mode & Med & Min & 5 & 0.7 \\
\hline Leadership & 5 & 5 & 3 & 5 & 0.5 \\
\hline Organizational Culture & 5 & 5 & 4 & 5 & 0.6 \\
\hline Development of Personnel & 4 & 4 & 3 & 5 & 0.5 \\
\hline Strategic Planning & 5 & 5 & 4 & 5 & 0.7 \\
\hline Organizational Structure & 4 & 4 & 3 & 5 & 0.5 \\
\hline Control Systems & 5 & 5 & 4 & 5 & 0.8 \\
\hline Governance & 4 & 4 & 2 & 5 & \\
\hline
\end{tabular}

research, and using the measures owners and CEOs were willing to share, revenue growth rate, profit growth rate and revenue per employee were the measures used to assess performance. The respondents provided actual revenues, profits (EBIT) and in most cases employee counts. Growth rates were calculated from this information. Respondents were not as precise with employee numbers as with financial data, often giving approximations of staffing. Consequently, only revenue and profit growth rates were used in the statistical analysis. There is considerable debate as to what constitutes performance with respect to management systems (Huselid, 1995) and what and how certain independent variables contribute to enterprise success and performance (Kumar \& Zattoni, 2014; Quigley \& Hambrick, 2015).

Senge and others have noted that financial measures are not necessarily the best measures of system health and effectiveness, however, they are the most universal (Deming, 1982; Kaplan \& Norton, 2008; Rouse, 2011; Senge, 1990b), and in the case of this research, the only non-ordinal data collected.

Anecdotal evidence of efficacy from using the elements is echoed in the financial results and the opinions of the respondents. Over the study period, 2007 to 2013, average revenue growth was reported to be $116 \%$, and average profit growth rate was reported to be $95 \%$. It should be noted this period includes the greatest recession in US history and the participants included companies in real estate, construction, mechanical contracting and leisure and travel, some of the hardest-hit industries. During this same period average growth of US Gross Domestic Product (GDP) was $0.73 \%$ (Young, 2013). The respondents reported an average revenue growth rate of $116 \%$. Sample sizes proved to be too small to infer any statistical significance.

Specific comments and opinions advanced by the respondents speak to the efficacy of the common elements in enterprise performance. Below are some representative responses:

"The impact on our growth rates is impossible to discern, but I believe using the framework as a system has caused me to focus on the areas where I can have the greatest impact. The elements individually created great value for me, but as a system the framework transforms my company's performance."
"Without these elements used as a system, we probably would not have survived."

"The results over the last nine years, especially in the area of profitability, but also in hiring and development of our people and overall quality of programs in marketing, sales and logistics - without a doubt our enterprise has been enhanced by using the elements and the model."

"Using the model, we have excelled comparatively to our peers (growth in the business (enrolments and revenue), growth in net assets, etc. and are consistently identified as the best place to work based on employee surveys."

\section{CONCLUSIONS}

From the research into the most common elements of the most common enterprise management models, it appears there is evidence of an archetypal set of elements. There are several implications for owners and managers in these findings:

1. There was variability in the descriptions and uses of each element revealed in the research. These slight variations are not problematic firm to firm; however, it is imperative to clearly describe and define the elements chosen within a given firm so that all occupants reach a common language and common mental models.

2. Whether managers choose a named framework, use the one described herein, or create their own, which framework they choose is not as important as assuring that the common elements all have coverage.

3. Managers must view the chosen framework and the elements of that framework as a system and use it consistently in such a manner.

4. Managers must train all system occupants in the language and use of the system for full effectiveness.

Owners and managers should not abandon all past affinity to current models and frameworks. The keys are to assure that the common elemental coverage is in place, the framework is used as a system, and the system and elements are known and understood by all. 


\section{IMPLICATIONS FOR SMALL BUSINESS}

The reader might be tempted to say that the findings described here are not germane to small businesses as small business owners and operators are in some ways at a significant disadvantage relative to their larger more established counterparts. They do not have access to corporate universities and consultants. However, the systemic and archetypal nature of the findings are the compelling feature for small businesses. Each of the common elements described herein will be in place in a small business either by default or by design. There will be a governance function in place even in a sole proprietorship where the owner represents the governance element alone. The operative question is whether that default setting is effective? If not, perhaps the owner should empanel a board of advisors to assist with important governance issues. Similarly, in that same sole proprietorship there will be a planning system, perhaps that system is to not plan at all, but is it effective and appropriate? Even in a small firm, there will be a default leadership system and style. But is it effective and appropriate? Does it integrate with all the other elements in a systemic way? All the common elements found in this research will be in place in a small business precisely because they are elemental and must be in place for the system to function. Some elements, such as the culture and leadership style, are emergent properties of the system that arise precisely because the system elements are brought together (Meadows, 2008). Nothing keeps a small business from thinking about the common elements and assuring that all employees, regardless of number, are aware of the system elements and have common mental models and language. In fact, that is precisely what the consultants would have them do if they were big enough to engage them. The danger in the proliferation of management guidance is that small business owners often gravitate to the latest or most alluring trends without assuring that they are appropriate to their system and the elemental systems components already in play in their system.

Submitted: March 26, 2020 MST, Accepted: September 11, 2021 MST 


\section{REFERENCES}

Abel, A. L., \& Li, J. (2012). Exploring the Corporate University Phenomenon: Development and Implementation of a Comprehensive Survey. Human Resource Development Quarterly, 23(1), 103-128. eric.

Ackoff, R. L. (1971). Towards a System of System Concepts. Management Science, 17(11), 661-671. bth.

Ackoff, R. L. (1999). Re-creating the Corporation: A design of Organizations for the 21st Century. Oxford University Press.

Adkins, A. (2016). Employee Engagement in U.S. Stagnant in 2015. Gallup. https://news.gallup.com/poll/188144/ employee-engagement-stagnant-2015.aspx

Allen, M. (2002). The Corporate University Handbook: Designing, Managing, and Growing a Successful Program. AMACOM; Cat00235a. http://proxygw.wrlc.o rg/login?url=http://search.ebscohost.com/login.asp $\underline{x}$ ?direct $=$ true $\& d b=c a t 00235 a \& A N=g w u .4008275 \&$ sit $\mathrm{e}=$ eds-live \&scope $=$ site

Arnold, S., \& Lawson, H. W. (2004). Viewing systems from a business management perspective: The ISO/ IEC 15288 standard. Systems Engineering, 7(3), 229. eda.

Atwater, J. B., Kannan, V. R., \& Stephens, A. A. (2008). Cultivating Systemic Thinking in the Next Generation of Business Leaders. Academy of Management Learning \& Education, 7(1), 9-25. bth. https://doi.org/10.5465/ amle.2008.31413859

Bardoel, E. A., \& Haslett, T. (2004). Success to the Successful: The Use of Systems Thinking Tools in Teaching OB. Organization Management Journal, 1(2), 112-124. bth.

Blake, R. R., \& Mouton, J. S. (1969). Building a dynamic corporation through grid organization development. Addison-Wesley Pub. Co.

Bolman, L. G., \& Deal, T. E. (1984). Modern approaches to understanding and managing organizations (1st ed). Jossey-Bass.

Bryan, L. (2008). Enduring Ideas: The 7-S framework. McKinsey Quarterly, 1, 112-112. bth.

Burke, W. W., \& Litwin, G. H. (1992). A causal model of organizational performance and change. Journal of Management, 18(3), 523-545. psyh. https://doi.org/1 $\underline{0.1177 / 014920639201800306}$

Cachia, M., \& Millward, L. (2011). The telephone medium and semi-structured interviews: a complementary fit. Qualitative Research in Organizations and Management, 6(3), 265-277. ABI/ INFORM Complete. https://doi.org/10.1108/17465641 $\underline{111188420}$

Chan, J. O. (2009). A Conceptual Framework for an Integrated Knowledge-Driven Enterprise Model. Journal of International Technology and Information Management, 18(2), 161-185. ABI/INFORM Complete.

Checkland, P. B. (1971). A systems map of the universe. Journal of Systems Engineering, 2. Edsref. http://prox ygw.wrlc.org/login?url=http://search.ebscohost.com/1 ogin.aspx?direct=true $\& \mathrm{db}=$ edsref \&AN=AJHDGAFC $\underline{\text { C\&site }=\text { eds-live \&scope }=\text { site }}$
Checkland, P. B. (1999). Systems Thinking, Systems Practice. John Wiley \& Sons, LTD.

Checkland, P. B., \& Haynes, M. G. (1994). Varieties of systems thinking: the case of soft systems methodology. System Dynamics Review (Wiley), 10(2/ 3), 189-197. bth.

Churchman, C. W. (1979). The Systems Approach and Its Enemies (First). Basic Books, Inc.

Collins, J. (2001). Good to Great: Why Some Companies Make the Leap and Others Don't. Harper Collins.

Collins, J., \& Porras, J. I. (1994). Built to last: successful habits of visionary companies. Harper Collins.

Creswell, J. W. (2003). Research Design - Qualitative, Quantitative and Mixed Methods Approaches (Second). Sage Publications, Inc.

Creswell, J. W. (2007). Qualitative Inquiry \& Research Design: Choosing Among Five Approaches (Second). Sage Publications, Inc.

de Weck, O. L., Roos, D., \& Magee, C. L. (2011). Engineering Systems. The MIT Press.

Deming, W. E. (1982). Out of the Crisis. Massachusetts Institute of Technology.

Deming, W. E. (1994). The New Economics (2nd ed.). MIT, Center for Advanced Educational Services.

Drucker, P. F. (2001). The Essential Drucker. Harper Collins.

Freedman, A. M. (2011). Using Action Learning for Organization Development and Change. $O D$ Practitioner, 43(2), 7-13.

Fyock, C. D. (1999). If Only We Knew What We Know: The Transfer of Internal Knowledge and Best Practice. HRMagazine, 44(5), 134-134. ABI/INFORM Complete; ABI/INFORM Complete; ProQuest Research Library; ProQuest Research Library.

Galbraith, J. R. (2002). Organizing to Deliver Solutions. Organizational Dynamics, 31(2), 194-207. https://do i.org/10.1016/S0090-2616(02)00101-8

Gharajedaghi, J. (2006). Systems Thinking: Managing Chaos and Complexity: A Platform for Designing Business Architecture (Second). Butterworth Heinemann.

Goldratt, E. M. (1984). The Goal: A Process of Ongoing Improvement. North River Press.

Hanna, D. P. (1988). Designing Organizations for High Performance (Vol. 1). Pearson - Prentice Hall.

Hoebeke, L. (1994). Making Work Systems Better. Wiley.

Huselid, M. A. (1995). The impact of human resource management practices on turnover, productivity, and corporate financial performance. Academy of Management Journal, 38(3), 635. ProQuest Research Library.

Jackson, M. C. (2003). Systems Thinking - Creative Holism for Managers. John Wiley \& Sons, LTD.

Jick, T., \& Peiperl, M. (2010). Managing Change: Cases and Concepts (3rd ed.). McGraw Hill. 
Kaplan, R. S. (2005). How the balanced scorecard complements the McKinsey 7-S model. Strategy \& Leadership, 33(3), 41-46. bth.

Kaplan, R. S., \& Norton, D. P. (2007). Using the Balanced Scorecard as a Strategic Management System. Harvard Business Review, 85(7/8), 11.

Kaplan, R. S., \& Norton, D. P. (2008). Mastering the Management System. Harvard Business Review, 86(1), 62-77. bth.

Keenoy, T., Marshak, R. J., Oswick, C., \& Grant, D. (2000). The discourses of organizing. The Journal of Applied Behavioral Science, 36(2), 133. ABI/INFORM Complete.

Kilmann, R. H. (1986). Beyond the Quick Fix: Managing Five Tracks to Organizational Success. Organization Studies, 7(1), 96.

Koestler, A. (1967). The Ghost in the Machine (1990 reprint edition). Penguin Group.

Kotter, J. P. (2007). Leading Change: Why Transformation Efforts Fail. Harvard Business Review, May-June, 92-107.

Kumar, P., \& Zattoni, A. (2014). Ownership, Managerial Entrenchment, and Corporate Performance. Corporate Governance: An International Review, 22(1), 1-3. http s://doi.org/10.1111/corg.12053

Leavitt, H. J. (1962). Management According to Task: Organizational Differentiation. Management International, 2(1), 13-22.

Leedy, P. D. (1997). Practical Research - Planning and Design (Sixth). Prentice-Hall. Inc.

Levitt, B., \& March, J. G. (1988). Organizational Learning. Annual Review of Sociology, 14, 319-340. edsjaa.

Meadows, D. H. (2008). Thinking in Systems: A primer. Sustainability Institute.

Morgan, G. (1980). Paradigms, Metaphors, and Puzzle Solving in Organization Theory. Administrative Science Quarterly, 25(4), 605-622. https://doi.org/10.2 307/2392283

Nadler, D. A., \& Tushman, M. L. (1980). A model for diagnosing organizational behavior. Organizational Dynamics, 9(2), 35-51. https://doi.org/10.1016/0090-2 616(80)90039-X

NCCS Core Statistics. (2015). The National Center for Charitable Statistics. https://nccs.urban.org/sites/all/ nccs-archive/html/

Page, L., Brin, S., Motwani, R., \& Winograd, T. (1999). The PageRank Citation Ranking: Bringing Order to the Web. http://ilpubs.stanford.edu:8090/422/

Pennock, M. J., \& Rouse, W. B. (2016). The Epistemology of Enterprises. Systems Engineering, 19(1), 24-43. http s://doi.org/10.1002/sys.21335

Porterfield, R. (2009). Management by bestseller: Make sure "change" is what you need. Dallas Business Journal. http://bizjournals.com

Quigley, T. J., \& Hambrick, D. C. (2015). Has the "CEO effect" increased in recent decades? A new explanation for the great rise in America's attention to corporate leaders. Strategic Management Journal, 36(6), 821-830. https://doi.org/10.1002/smj.2258
Rouse, W. B. (2005). Enterprises as systems: Essential challenges and approaches to transformation. Systems Engineering, 8(2), 138. eda.

Rouse, W. B. (2011). Necessary Competencies for Transforming an Enterprise. Journal of Enterprise Transformation, 1(1), 71-92. https://doi.org/10.1080/1 9488289.2010.548905

Rouse, W. B., \& Morris, N. M. (1986). On looking into the black box: Prospects and limits in the search for mental models. Psychological Bulletin, 100(3), 349-363. pdh. https://doi.org/10.1037/0033-2909.10 $\underline{0.3 .349}$

Schwaninger, M. (2001). Intelligent organizations: an integrative framework. Systems Research and Behavioral Science, 18(2), 137-158. ABI/INFORM Complete; ABI/INFORM Complete.

Segatto, M., Silvia Inês Dallavalle de, P., \& Dante Pinheiro, M. (2013). Business process management: a systemic approach? Business Process Management Journal, 19(4), 698-714. ABI/INFORM Complete. http s://doi.org/10.1108/BPMI-Jun-2012-0064

Senge, P. M. (1990a). The Fifth Discipline: The Art and Practice of the Learning Organization. Doubleday.

Senge, P. M. (1990b). The Leader's New Work: Building Learning Organizations. Sloan Management Review, 32(1), 7. ABI/INFORM Complete; ABI/INFORM Complete; Banking Information Source; ProQuest Research Library; ProQuest Research Library; ProQuest Telecommunications.

Senge, P. M., Roberts, C., Ross, R. B., Smith, B. J., \& Kleiner, A. (1994). The Fifth Discipline Fieldbook: Strategies and tools for building a learning organization. Doubleday.

Statistics of U.S. Businesses (SUSB). (2015). https://www.c ensus.gov/programs-surveys/susb.html

Stewart, P. J., Shaw, M. S., \& Blass, E. (2005). The rise and rise of the corporate university. JOURNAL OF EUROPEAN INDUSTRIAL TRAINING, 29(1), 58-74. edsbl.

Storey, J. (2004). Leadership development through corporate universities. Training and Management Development Methods, 18, 41-49. edsref.

Weisbord, M. R. (1976). Diagnosing your organization: A "six-box" learning exercise / by Marvin R. Weisbord. Wynnewood, Pa.: Organization Research \& Development, c1976.; cat00408a. http://proxygw.wrlc.o rg/login?url=http://search.ebscohost.com/login.asp $\underline{\mathrm{x}}$ ?direct $=$ true $\& \mathrm{db}=\mathrm{cat} 00408 \mathrm{a} \& \mathrm{AN}=\mathrm{cu} .709502 \&$ site $=\mathrm{e}$ ds-live \&scope $=$ site

Wheatley, M. J. (2006). Leadership and the new science: Discovering order in a chaotic world (3rd ed.). BerretKoehler Publishers, Inc.

Whiting, L. S. (2008). Semi-structured interviews: guidance for novice researchers. Nursing Standard, 22(23), 35-40. ProQuest Career and Technical Education.

Yin, R. K. (2014). Case Study Research. Sage Publications, Inc. 
Young, J. T. (2013). The Worst Four Years Of GDP Growth

In History: Yes, We Should Be Worried. http://www.forb

es.com/sites/realspin/2013/04/12/the-worst-four-year s-of-gdp-growth-in-history-yes-we-should-be-worrie d/ 